\title{
SUCCESSFUL RECOVERY OF BREAST CANCER SCREENING AND DIAGNOSIS RATES DURING COVID-19 PANDEMIC BY ADOPTING THE RECOMMENDATIONS OF THE BRAZILIAN COLLEGE OF RADIOLOGISTS (CBR), THE BRAZILIAN FEDERATION OF GYNECOLOGISTS AND OBSTETRICIANS (FEBRASGO), AND THE BRAZILIAN MASTOLOGY SOCIETY (SBM): DATA FROM A PRIVATE BREAST UNIT IN BELO HORIZONTE, BRAZIL
}

Henrique Lia Couto1, Nayara Carvalho de Sá1, Rachel Saraiva Teatini Selim de Sales¹, Tereza Cristina Ferreira de Oliveira1, Patrícia Martins Gomes El Bacha', Shirley das Graças Ferreira', Gabriel de Almeida Silva Junior¹, Carolina Nazareth Valadares ${ }^{1}$

${ }^{1}$ Clínica Radiológica Ambulatorial Redimasto, Redimama Ltda - Belo Horizonte (MG), Brazil.

Objectives: To present the results of adopting CBR/FEBRASGO/SBM recommendations for breast cancer screening and diagnosis during 2020 COVID-19 PANDEMIC on mammograms (MMG), breast ultrasound (BUS), breast biopsy (BB), and cancer diagnosis (CD) rates. Methodology: Comparing by month the total number of MMG, BUS, BB (composed of fine needle, core, and vacuum procedures), and invasive and in situ cancers diagnosis (CD) performed at Redimama, a private breast unit from Belo Horizonte Brazil, that adopted CBR/FEBRASGO/SBM recommendations for breast cancer screening and diagnosis during the 2020 COVID-19 pandemic year to 2019 same period. Results: In April 2019, 391 MMG, 714 BUS, 223 BB, and 22 CD were performed, compared with 115 (29.4\%) MMG, 313 (43.8\%) BUS, 116 (52\%) BB, and 11 (50\%) $\mathrm{CD}$ in 2020. A continuous and fast recovery occurred along the time. In 2019 first semester, 2241 MMG, 4229 BUS, 1214 BB, and 84 CD were performed, compared with 1,903 (88.7\%) MMG, 4,227 (99.2\%) BUS, 1,044 (86\%) BB, and 92 (109.5\%) DC in 2020. In 2019, 4,424 MMG, 10,395 BUS, 3,304 BB, and 231 CD were performed, compared with 4,561 (110.79\%) MMG, 11,549 (120.72\%) BUS, 3,011 (91.13\%) BB, and 226 (97.83\%) CD in 2020. In 2019, the median size in image (T) by MMG/BUS for invasive cancers (IC) was $18.18 \mathrm{~mm}$, from CD 184 (79.66\%) were IC, and 47 (20.4\%) ductal carcinoma in situ (DCIS) compared to a T of $18.2 \mathrm{~mm}, 191$ (86.52\%) IC, and 35 DCIS in 2020. Conclusion: Adopting the CBR/FEBRASGO/SBM recommendations for breast cancer screening and diagnosis results to recovery the prior pandemic levels. Recovery of MMG and BUS is faster and shows a "J" curve compared with recovery of BB and CD that shows a "'U”' curve with a delay. This strategy should be adopted in Brazil in order to maintain breast cancer screening and diagnosis.

Keywords: Breast Neoplasms; Screening; Mammograms; Breast Ultrasound; Biopsy. 